\title{
VIAJE AL OESTE. LA ASOCIACIÓN SINO-MEXICANA: UNA POSIBILIDAD FUNCIONALISTA
}

\author{
Francisco Javier Haro Navejas ${ }^{1}$ \\ Rosángel Hernández MendozA ${ }^{2}$
}

Con menos tribulaciones Que Xuanzang, el personaje principal de Viaje al Oeste, ${ }^{3}$ Enrique Peña Nieto, presidente de México (2012-2018), viajó a la República Popular China (en adelante, China o simplemente Beijing) a principios de 2013, para explicitar la voluntad de su gobierno para recomponer la relación bilateral con este país. Desde la perspectiva gubernamental china, la misma estaba dañada de forma severa por las acciones de los gobiernos de Vicente Fox (2000-2006) y Felipe Calderón (2006-2012).

Ya sea por no prestar atención adecuada a sus representantes diplomáticos o por carecer de los adecuados, los gobiernos mexicanos no han sabido responder correctamente a qué hacer con y respecto a China. En diferentes momentos, desde el primer viaje a Beijing de Luis Echeverría -considerado por diplomáticos chinos como el ícono de las relaciones sino-mexicanas- hasta la reciente visita de Xi Jinping a México, el ánimo de las relaciones bilaterales ha oscilado entre el entusiasmo y la decepción infundada.

1 Trabajos recientes: La nueva institucionalización mundial: China, India, Japón y Tailandia frente al TTP, La política exterior tailandesa y la construcción de un eje regional asiático, Does Illusion Free Ride on the Chinese Economy? A Pattern of Dependency in the CACZ.

${ }^{2}$ Recientemente publicó La dimensión institucional en la relación Ansea-ocs.

${ }^{3}$ Una de las obras más populares de la literatura china. 
Han existido enfrentamientos internos sobre qué hacer en Asia, ${ }^{4}$ como ocurrió en el gabinete de Fox, y un discurso cargado de valores de pretendida aplicación universal, como se vio con el énfasis en los derechos humanos del mismo Fox y del peso de la religión en su sucesor. ${ }^{5}$ El primero, una vez fuera de la presidencia, se ha olvidado de los valores enarbolados para convertirse en impulsor de cierto tipo de protoestudio sobre China ${ }^{6}$ y de casi todo tipo de inversión proveniente de ese país. ${ }^{7}$

Ni desde el punto de vista práctico, ni desde el teórico-conceptual, la relación sino-mexicana es tan importante como la que existe entre Beijing y otros países, como sería el caso de Japón. ${ }^{8}$ Sin embargo, desde la perspectiva académica, es oportuno ahondar en ella debido al viaje del presidente Peña Nieto a China (noviembre de 2014) y, particularmente, por el impulso que su gobierno le ha dado a esta relación, el cual se materializó en una pronta visita de Xi Jinping a México y en el establecimiento de una Asociación Estratégica Integral en junio de 2013, apenas dos meses después del primer viaje de Peña Nieto a China.

A partir de lo anterior, nuestro trabajo tiene como objetivo responder la pregunta: ¿hay elementos que permitan empezar a construir una etapa nueva y mejor en las relaciones entre México

${ }^{4}$ Romer Cornejo, "México y China: diplomacia, competencia económica y percepciones”, Foro Internacional, vol. 48, núms. 1-2, enero-junio de 2008, p. 336.

${ }^{5}$ Francisco Javier Haro, Religión y ciencia en las relaciones internacionales: El discurso en los intercambios gubernamentales sino-mexicanos, Inter-Asia Paper, núm. 24, 2011, Universidad Autónoma de Barcelona, versión electrónica en https://ddd. uab.cat/pub/intasipap/intasipap_a2011n24/intasipap_a2011n24p1.pdf

${ }^{6}$ Reporte 98.5, "Vicente Fox Quezada será anfitrión de inversionistas chinos que buscan socios en México" [audio], entrevista a Vicente Fox por Yuridia Sierra, http:/ / www.reporte.com.mx/vicente-fox-quezada-sera-anfitrion-de-inversionistaschinos-que-buscan-socios-en-mexico

${ }^{7}$ Ernesto Méndez, "Fox cabildea proyecto turístico por el que temen catástrofe ambiental”, Excélsior (en línea), 21 de mayo de 2014, http:/ /www.excelsior.com. $\mathrm{mx} / \mathrm{nacional} / 2014 / 05 / 21 / 960495$

${ }^{8}$ Björn Jerdén y Linus Hagström, "Rethinking Japan's China policy: Japan as an Accommodator in the Rise of China, 1978-2011”, Journal of East Asian Studies, vol. 12, núm. 2, 2012, pp. 215-250. 
y China? Contestar implica analizar y comprender los que aparecen como los actos más significativos de la recomposición de la relación: el inicio de la venta sistemática de crudo mexicano a China y el supuesto escalamiento que implicó pasar de tener una Asociación Estratégica a una Asociación Estratégica Integral.

Para conducir dicho análisis, abordamos los siguientes aspectos: inicialmente, discutimos los antecedentes inmediatos de la relación bilateral entre el gobierno chino y el mexicano, e introducimos el funcionalismo, enfoque teórico en el que nos apoyamos para analizar dicha relación. Después, explicamos en qué han consistido los cambios en política exterior planteados por el gobierno de Peña Nieto hacia China, los cuales contrastamos con la tradición gubernamental mexicana al respecto. A continuación, describimos y analizamos qué ha sido para Beijing la idea de las asociaciones estratégicas y su evolución en la relación con el gobierno mexicano. Posteriormente, nos ocupamos de analizar el aspecto institucional y la atomización de los actores en los ámbitos de calzado, minería y petróleo. Finalmente, esbozamos lo que podría representar la nueva Asociación Estratégica Integral para el futuro de la relación.

EL CAMINO HACIA LA PARSIMONIA CONCEPTUAL: FUNCIONALISMO Y ESTADO ACTUAL DE LA RELACIÓN

Para realizar el análisis propuesto, nos apoyaremos en elementos teóricos, pero no pretendemos pelear por una teoría por encima de otra. Consideramos que situaciones específicas requieren de instrumentos teóricos igualmente específicos. En la búsqueda de la parsimonia, esencial en toda construcción teórica, recuperamos aspectos esenciales del funcionalismo, tal y como como ha sido propuesto por Brent J. Steele. ${ }^{9}$

Lo que se ha dado en llamar funcionalismo, al menos como se recupera de Mitrany -considerado el principal exponente de este

${ }^{9}$ Brent J. Steele, "Revisiting Classical Functional Theory: Towards a TwentyFirst Century Micro-Politics", Journal of International Political Theory, vol. 7, núm. 1, 2011, pp. 16-39. 
enfoque-, consiste en un conjunto de postulados que argumentan que cooperación e integración internacionales son posibles, siempre y cuando se basen en el establecimiento de acuerdos para la realización de funciones específicas que, en una primera fase, estarían enfocadas a atender necesidades económicas o sociales, dejando fuera temas políticos. Ello permitiría evitar controversias de soberanía, que han sido el obstáculo principal para el progreso de otros enfoques de integración. De acuerdo al propio Mitrany, el enfoque funcionalista "ayudaría a cambiar el énfasis de asuntos políticos que dividen, hacia aquellos asuntos sociales en los cuales el interés de la gente es claramente afín y colectivo [...]." ${ }^{10}$ La gran meta de la estrategia funcionalista es que la cooperación en asuntos económicos o sociales impulse un proceso de aprendizaje y derramamiento (spillover) de la cooperación hacia temas políticos. ${ }^{11}$

El funcionalismo surgió a mediados del siglo pasado y ejerció una influencia importante en el desarrollo del sistema de agencias especializadas de la Organización de las Naciones Unidas. ${ }^{12}$ No obstante, para emplearlo en el análisis de temas contemporáneos, consideramos prudente recurrir a la "restauración y reconstrucción" de este enfoque, realizada por Steele. El componente central de dicha actualización es la asociación del funcionalismo con la micropolítica, ${ }^{13}$ como vía para enfatizar que los arreglos funcionales sólo serán útiles en un espacio y tiempo limitados. También establece que es prácticamente imposible extrapolarlos con éxito a otros casos y que, a diferencia del funcionalismo clásico de Mitrany, difícilmente podrían evolucionar hacia esquemas de cooperación e integración de largo plazo. ${ }^{14}$ Por su énfasis en la cooperación por

${ }^{10}$ David Mitrany, "The Functional Approach to World Organization", International Affairs, vol. 24, núm. 3, 1948, p. 359.

11 Ibid., pp. 359-360.

12 Peter Willetts, "The Cardoso Report on the UN and Civil Society: Functionalism, Global Corporatism, or Global Democracy?”, Global Governance, vol. 12, núm. 3, 2006, p. 312.

${ }^{13}$ Uno de los niveles de estudio de la política, cuyo objeto de análisis es el actor político individual o el grupo pequeño. Andrés Serra Rojas, Diccionario de Ciencia Política (M-Z), Facultad de Derecho, unam / FCE, México, 2001, p. 738.

${ }^{14}$ Steele, "Revisiting Classical...", pp. 32-35. 
medio de mecanismos funcionales para un espacio y tiempo delimitados, consideramos que este enfoque podría ser útil para estudiar la relación sino-mexicana, y plantear posibles soluciones a los problemas de la misma. ${ }^{15}$

Durante doce años, los funcionarios chinos enfrentaron diferentes dificultades, sobre todo relacionadas con el trato dado al Dalái Lama, con la actitud de algunos funcionarios mexicanos y con las declaraciones inoportunas de titulares del Ejecutivo mexicano, como Vicente Fox y Felipe Calderón. Para el gobierno de China y sectores progubernamentales: "Calderón hirió los sentimientos del pueblo chino" dos veces: una al entrevistarse en privado con el Dalái Lama y otra durante la epidemia AH 1 N 1, cuando el presidente y su secretaria de Relaciones Exteriores, Patricia Espinoza, se quejaron de la cancelación de vuelos provenientes de México, a la cual calificaron como una medida discriminatoria. ${ }^{16}$ Políticos y diplomáticos chinos exageraron el efecto de estos deslices y se victimizaron para aumentar sus ganancias en una negociación futura. ${ }^{17}$

Estas diferencias en ámbitos cercanos a lo político no impidieron que dicho periodo fuera el más fructífero en materia de construcción de instituciones para la cooperación en asuntos económicos. Entre el final del sexenio de Fox y el inicio del de Calderón, se crearon cuatro mecanismos de cooperación bilateral (véase el cuadro 3, infra). Lo anterior confirma la tesis funcionalista de que los acuerdos y mecanismos funcionales son los que

${ }^{15}$ Robert W. Cox, "Social Forces, States and World Orders: Beyond International Relations Theory”, en Robert O. Keohane (coord.), Neorealism and Its Critics, Nueva York, Columbia University Press, 1986, pp. 204-253.

${ }^{16}$ Yuanting Chen, "China y México, ¿socios rivales?”, China Hoy, 1 de marzo de 2012, http://www.chinatoday.mx/eco/clae/content/2012-03/01/content_42 9288.htm

${ }^{17}$ Para el gobierno chino, la victimización ha sido una herramienta muy versátil: por un lado, ha sido un componente esencial de la construcción identitaria dominante alrededor de la interpretación de las Guerras del Opio desde 1838; y por otro, un arma de negociación para obtener lo más posible de su contraparte, como es el caso alrededor del tema de la asistencia oficial para el desarrollo que recibe de Japón y otros países, o dentro de la Organización Mundial del Comercio, respecto al tipo de economía existente en China. 
pueden transformar la dependencia relativa existente en una interdependencia que permita a la mayoría de los actores maximizar sus ganancias. Esto será posible si las partes se concentran en funciones-actividades particulares y específicas. ${ }^{18}$

\section{LA NUEVA-VIEJA POLÍTICA EXTERIOR ACTIVA}

Para apaciguar al gobierno chino y recomponer la relación política, Peña Nieto, más cercano a la complacencia y a la Realpolitik que sus antecesores, se planteó como una prioridad acercarse a Beijing. Con ese objetivo, viajó a Sanya, Hainan, en abril de 2013, para participar en el Foro Bo'ao. En su mensaje principal durante dicho foro, Peña Nieto asignó a China una identidad positiva en un doble sentido: como "potencia económica" y como "fuente de estabilidad global". Además, el mandatario mexicano manifestó su deseo de iniciar una nueva relación, y en un intento por equilibrar la balanza geopolítica, anunció que México pretendía integrarse a la "dinámica Región de Asia", para lo cual impulsó la Alianza del Pacífico, al lado de Chile, Colombia y Perú. ${ }^{19}$

Ello nos permite señalar que el primer cambio sustantivo respecto a China, y que diferencia al gobierno de Peña de sus antecesores inmediatos, fue en el nivel discursivo. Sin embargo, lo más importante de los pasos dados fue en materia de recompensas mutuas, aunque asimétricas. En sustitución de Jorge Guajardo, se nombró como embajador en Beijing, a Julián Ventura, un diplomático de carrera con las credenciales necesarias para, en teoría, mejorar el manejo de la compleja relación con China. También se concretaron acuerdos más cercanos a intereses empresariales y gubernamentales chinos, como los firmados con Petróleos Mexica-

${ }^{18}$ Chris Brown y Kirsten Ainley, Understanding International Relations, $3^{\text {a }}$ ed., Nueva York, Palgrave, 2005, p. 119.

${ }^{19}$ Presidencia de la República, "Inauguración de la Conferencia Anual 2013, Asia buscando el desarrollo para todos: reestructurando, responsabilidad y cooperación", http:/ / www.presidencia.gob.mx/articulos-prensa/inauguracion-de-laconferencia-anual-2013-asia-buscando-el-desarrollo-para-todos-reestructurandoresponsabilidad-y-cooperacion/ 
nos (PEMEX) para la exportación de crudo. En respuesta, el gobierno chino ofreció facilidades para la exportación de carne de cerdo y de tequila $100 \%$ de agave. Desde una perspectiva funcionalista, y tomando en cuenta la integración prácticamente inexistente, los pasos dados abren posibilidades para debilitar la asimetría.

Desde un enfoque institucional-realista, han sido cuatro décadas durante las cuales, por un lado, la relación bilateral es cada vez más fuerte institucionalmente y, por el otro, la asimetría estuvo repartida de forma equilibrada sobre todo en la década de 1970 y parte de la de 1980: Beijing predominaba en lo político, impuso lo esencial de su agenda política a través de la aceptación mexicana de la política de una sola China; a su vez, los mexicanos dominaron en lo económico. En la actualidad, la asimetría es desfavorable a México, tanto en lo económico como en lo político. Dos variables son esenciales para sustentar esa afirmación: el creciente superávit comercial favorable a los asiáticos, a la par de la participación comercial china cada vez mayor en el comercio total mexicano, y el lugar que cada uno de ellos ocupa en el sistema internacional y en el mercado mundial.

Si bien los patrones conductuales del pasado no garantizan que los mismos se repetirán hasta el infinito, sí es necesario analizarlos para comprender, al menos parcialmente, lo que hacen los gobernantes en un momento determinado o qué influye sobre sus acciones y preferencias futuras. A partir de lo anterior, podemos señalar que la política de acercamiento a China que ha propuesto Peña Nieto no es nueva. En el marco de los ciclos sexenales, es común que al inicio de los mismos los mandatarios entrantes lancen múltiples propuestas de política exterior con pretensiones innovadoras.

Los sexenios están llenos de vaivenes, continuidades y rupturas, aparentemente caprichosas. Esta situación ha llevado a buscar la continuidad legal de la política exterior, a fin de que ésta sea una "política de Estado" y no de gobierno-partido. De acuerdo a esta aspiración, el artículo 26 de la Constitución mexicana establece la necesidad de elaborar un Plan Nacional de Desarrollo (PND) que garantice la continuidad de la actividad gubernamental y que la rija. El PND sustituye a los planes 
sexenales iniciados con Lázaro Cárdenas (1934-1940) y finalizados con José López Portillo (1976-1982).

Además de contener el proyecto de desarrollo económico y social de la nación, los PND incluyen un conjunto de ideas generales con las que se pretende ordenar la puesta en acción de la política exterior. Ahí encontramos un patrón discursivo, en el que varios presidentes se han presentado como impulsores de una política exterior activa. ${ }^{20} \mathrm{Ni}$ los gobernantes panistas, Fox y Calderón, ni el actual presidente Peña Nieto han evitado este discurso que tiene como primer antecedente a Adolfo López Mateos (1958-1964).

En el PND de su presidencia, fechado 2001-2006, Vicente Fox propuso llevar a cabo una "política exterior proactiva"; ${ }^{21}$ y su sucesor, Felipe Calderón (2007-2012), habló de una "política exterior responsable, definida y activa”. ${ }^{22}$ En el PND 2013-2018, Peña Nieto plantea que la defensa y promoción del interés nacional de México en el exterior estará sustentada en una "política exterior vigorosa, sustantiva y activa”. ${ }^{23}$ En el documento central para guiar el trabajo de la burocracia federal, los cambios aunque son formales, no evitan que en la práctica y por encima de una visión de Estado, las acciones gubernamentales puedan ser moldeadas a partir de una combinación de ideas más o menos personales y, en la mayoría de los casos, repetitivas.

Unida a la idea del activismo diplomático convertida en práctica transexenal, también es posible encontrar en los PND, una preocupación por la diversificación de las relaciones exteriores mexicanas, asociada a un acercamiento a la región de Asia-Pací-

${ }^{20}$ Ana Covarrubias, "La política exterior "activa”... una vez más”, Foro Internacional, vol. 48, núms. 191-192, 2008, p. 13.

${ }^{21}$ Véase el apartado 2.2 del PND 2001-2006, http://www.dof.gob.mx/nota detalle.php? codigo $=766335 \&$ fecha $=30 / 05 / 2001$

${ }^{22}$ Véase el apartado "Eje 5. Democracia efectiva y política exterior responsable" del PND 2007-2012, http://www.dof.gob.mx/nota_detalle.php?codigo=4989 401 \&fecha $=31 / 05 / 2007$

23 Véase el apartado "V. México Con Responsabilidad Global" del PND 2013-2018, http:/ / www.dof.gob.mx/nota_detalle.php?codigo=5299465\&fecha= $20 / 05 / 2013$ 
fico. ${ }^{24}$ A la par, encontramos en los PND, con excepción del de Fox, propuestas específicas para ampliar y fortalecer los vínculos con China (véase el cuadro 1). Es decir, a nivel formal, la búsqueda de un acercamiento con China ha sido un proyecto de política exterior de México desde la década de 1980.

Resulta paradójico que finalmente se vislumbra la diversificación comercial limitada y unilateral, pero que no ha sido producto de las políticas planteadas en los PND. De manera consistente, los intercambios comerciales con China significan, primero, un ligero descenso de la importancia estadounidense y un aumento relativamente considerable de la presencia china; segundo, que las importaciones son casi iguales al total de lo intercambiado. La situación no es solamente producto de la avidez de los empresarios chinos por nuevos mercados, sino también de la de algunos actores económicos mexicanos, como los que están detrás del controvertido proyecto Dragon Mart, y otros que dependen de la importación de productos chinos para manufacturar mercancías a precios competitivos.

Tanto por ofrecer un marco de ideas para la continuidad del ideario del régimen anterior al de los panistas, como por la ventaja que representa navegar en el entorno internacional con ideas ya probadas como funcionales, el gobierno de Peña Nieto ha recurrido a fórmulas del pasado para "reactivar" la política exterior y lograr un mayor acercamiento con Asia-Pacífico, y con China en particular. Lo anterior se hace en detrimento de dejar fuera, por razones no explicitadas, a países potencialmente importantes como la India y Tailandia, o de gran trascendencia histórica y aun cardinal en términos de inversiones o cooperación, como es el caso de Japón, en donde queda mucho por hacer.

${ }^{24}$ La forma de referirse a esta región fue cambiando con el tiempo. En el PND 1989-1994, era la "Cuenca del Pacífico", en el PND 1995-2000 era el "Pacífico Asiático", y a partir del PND 2001-2006 hasta el actual PND 2013-2018, ha sido "Asia-Pacífico". Para una discusión sobre este concepto, véase Mercedes de Vega (coord.), Historia de las relaciones internacionales de México, 18212010 (volumen 6: Asia), México, Secretaría de Relaciones Exteriores, 2011, $42-43$. 


\section{CuAdro 1}

Referencias a China en los PND, 1983-2018

\begin{tabular}{|c|c|}
\hline$P N D$ & Referencia a China \\
\hline 1983-1988 & $\begin{array}{l}\text { "Con este conjunto de países, en que por la naturaleza de los ac- } \\
\text { tuales intercambios sobresalen entre otros, la India y la República } \\
\text { Popular China, se buscará en particular una coordinación en aque- } \\
\text { llas cuestiones internacionales en las que compartimos los mismos } \\
\text { planteamientos y aspiraciones." }\end{array}$ \\
\hline 1989-1994 & $\begin{array}{l}\text { “... [S] e propiciará una participación y un diálogo ampliados con la } \\
\text { República Popular China." }\end{array}$ \\
\hline 1995-2000 & $\begin{array}{l}\text { “...[B] uscaremos establecer vínculos más estrechos con la República } \\
\text { Popular de China, con el fin de multiplicar las oportunidades de } \\
\text { intercambio comercial con esa nación." }\end{array}$ \\
\hline 2001-2006 & Sin referencia directa. \\
\hline 2007-2012 & $\begin{array}{l}\text { "Estrategia 8.5... fortalecer los vínculos con China, Japón, India, } \\
\text { Corea, Singapur, Australia y Nueva Zelanda." }\end{array}$ \\
\hline 2013-2018 & $\begin{array}{l}\text { "México tiene el reto de llevar las relaciones con dicho país [China] } \\
\text { hacia un nuevo paradigma de cooperación y diálogo, que permita } \\
\text { propiciar nuevos esquemas de entendimiento e intercambio". }\end{array}$ \\
\hline
\end{tabular}

Fuente: Elaboración propia con información de los PND de varios años: 19831988, 1989-1994, 1995-2000, 2007-2012 y 2013-2018.

No obstante debilidades u omisiones, el gobierno de Peña Nieto ha realizado algunas acciones que respaldan su discurso. Por ejemplo, el patrón dominante es que los presidentes mexicanos viajen a China a partir del segundo o tercer año de gobierno. Sin embargo, Peña Nieto, en menos de un año, viajó a China, recibió al presidente chino en visita de Estado y se reunió nuevamente con él en septiembre de 2013, durante la Cumbre del G20 en Rusia, y realizó una visita de Estado a China en noviembre de 2014, la cual se preparó con considerable antelación, luego de su participación en la reunión de líderes del Foro para la Cooperación de Asia Pacífico (APEC, por sus siglas en inglés), que se llevó a cabo en Beijing. En lo que puede considerarse como muestra de la renovada actitud del gobierno chino hacia el mexicano, su embajador, Qiu Xiaoqi, ha comentado que durante dicha visita "el presidente recibirá todas las atenciones de protocolo de parte 
del gobierno chino" y que ésta "será una visita con muchos contenidos concretos". ${ }^{25}$

Asociación estratégica INTEgral MéXico-China: DE DÓNDE VIENE Y A HACIA DÓNDE PODRÍA IR

Cosechando del trabajo de negociaciones anteriores, pero sobre todo por contar con la capacidad para aprovechar el momento oportuno y alentar la diversificación, durante la reciente visita de Xi a México. Ambos gobiernos firmaron doce memorandos de entendimiento y lograron los acuerdos necesarios para exportar carne de cerdo y tequila a China. Además, enmarcado en la doble lógica de darle continuidad al entramado institucional levantado en más de cuatro décadas de relaciones bilaterales y de mostrar el nuevo momento de la relación, se anunció el establecimiento de una Asociación Estratégica Integral.

Hasta mediados de 2014, China sostenía asociaciones similares con más de cincuenta países y organizaciones, lo que hace de ellas una de las herramientas diplomáticas más empleadas por su gobierno. En América Latina ha establecido asociaciones con seis países, las cuales han recibido diferentes actualizaciones con el paso de los años (véase el cuadro 2). En el caso de México, han sido tres: la primera fue una Asociación de Cooperación Integral, en 1997; posteriormente, una Asociación Estratégica en 2003, la cual fue recientemente elevada a una Asociación Estratégica Integral en junio de 2013.

A pesar de lo anterior, la discusión sobre la política exterior china ha prestado poca atención a esta estrategia. ${ }^{26}$ La mayoría de

${ }^{25}$ El Colegio de México, "Segundo congreso internacional sobre la enseñanza del chino" [archivo de video], Intervención del Embajador Qiu Xiaoqi [min.4.30], YouTube, 12 de marzo de 2014, https:/ /www.youtube.com/watch?v=6 U0ggvLgjTc\&list=PLhIF5xewDHRxP1DKdN7HS2pRhCZe_gWUX\&index=4

${ }^{26}$ Eduardo Daniel Oviedo, "China: visión y práctica de sus llamadas relaciones estratégicas”, Estudios de Asia y África, vol. 41, núm. 3, septiembre-diciembre de 2006, pp. 385-404; y Avery Goldstein, “The Diplomatic Face of China's Grand Strategy: A Rising Power's Emerging Choice”, The China Quarterly, núm. 168, diciembre de 2001, pp. 835-864. 
los estudios sobre el tema analizan los casos significativos, como la Asociación Estratégica China-Unión Europea y la Asociación China-Rusia. ${ }^{27}$ De forma similar, en la bibliografía sobre las relaciones México-China, existen pocos análisis sobre el impacto y trascendencia de las diferentes asociaciones que se han establecido en el contexto de la relación.

\section{Cuadro 2}

Asociaciones de China con países latinoamericanos

\begin{tabular}{|c|c|c|}
\hline Inicio & País & Evolución \\
\hline 1993 & Brasil & 1993: Asociación Estratégica \\
\hline 1997 & México & $\begin{array}{l}\text { 1997: Asociación de Cooperación Integral } \\
\text { 2003: Asociación Estratégica } \\
\text { 2013: Asociación Estratégica Integral }\end{array}$ \\
\hline 2001 & Venezuela & $\begin{array}{l}\text { 2001: Asociación Estratégica por el Desarrollo Conjunto } \\
\text { 2014: Asociación Estratégica Integral }\end{array}$ \\
\hline 2004 & Argentina & $\begin{array}{l}\text { 2004: Asociación Estratégica } \\
\text { 2014: Asociación Estratégica Integral }\end{array}$ \\
\hline 2004 & Chile & $\begin{array}{l}\text { 2004: Asociación de Cooperación Integral } \\
\text { 2012: Asociación Estratégica }\end{array}$ \\
\hline 2005 & Perú & $\begin{array}{l}\text { 2005: Asociación de Cooperación Integral } \\
\text { 2013: Asociación Estratégica Integral }\end{array}$ \\
\hline
\end{tabular}

Fuente: elaboración propia con base en Oviedo, "China...”, p. 393; Ministerio de Relaciones Exteriores de la República Popular China, "Xi Jinping Holds Talks with President Cristina Fernández...”, y Ministerio de Relaciones Exteriores de la República Popular China, "Xi Jinping Holds Talks with President Nicolás Maduro of Venezuela...".

${ }^{27}$ Manuel de Jesús Rocha Pino, "La simetría en la Asociación Estratégica República Popular China-Unión Europea”, Estudios de Asia y África, vol. 45, núm.1, enero-abril de 2010, pp. 117-158; Yong Deng, "Remolding great power politics: China's strategic partnerships with Russia, the European Union, and India”, Journal of Strategic Studies, vol.30, núms. 4-5, 2007, pp. 863-903; Li Chenyang, "China-Myanmar Comprehensive Strategic Cooperative Partnership: A Regional Threat?”, Journal of Current Southeast Asian Affairs, vol. 31, núm. 1, 2012, pp. 53-72; Bobo Lo, "The Long Sunset of Strategic Partnership: Russia's Evolving China Policy", International Affairs, vol. 80, núm. 2, marzo de 2004, pp. 295-309; y Jennifer Anderson, The Limits of the Sino-Russian Strategic Partnership, Adelphi Paper 315, Nueva York, Oxford University Press, 1997, p. 94. 
En razón de lo anterior, y considerando que uno de los principales anuncios realizados durante la visita de Xi Jinping a México fue el cambio de nivel de su asociación, es oportuno detenernos a observar con atención estos mecanismos. Para ello hemos dividido la presente sección en dos partes. En la primera, analizamos las características generales de las asociaciones chinas y discutimos los objetivos de política exterior que pueden estar detrás de ellas. En la segunda, exponemos algunos de los eventos principales que han ocurrido en la relación México-China a partir de 1997, prestando atención especial al contexto en el que han sido establecidas las asociaciones.

\section{Características generales de las asociaciones estratégicas de China}

La década de 1980 terminó con un gobierno chino ante condiciones complicadas como consecuencia de una combinación de efectos provocados por la apertura y la reforma económica emprendidas en este país desde finales de la década de 1970: inflación creciente, descontento social, corrupción e incapacidad gubernamental para destrabar los obstáculos que permitieran profundizar los cambios. Mientras que los grupos sociales movilizados fueron incapaces de imponer algunos puntos de su agenda, el gobierno respondió violentamente en diferentes niveles, del cual el más famoso fue la entrada del ejército a Tian'anmen, en la madrugada del 4 de junio de 1989. A ello se sumarían las reacciones de condena de diferentes gobiernos extranjeros, que aunque fueron más discursivas que materiales, afectaron la imagen del gobierno chino, por el fortalecimiento de las percepciones negativas.

La salida del laberinto aparente fue encontrada fuera de sus fronteras. A inicios de los noventa, el gobierno chino, apoyado por una creciente comunidad empresarial, logró hacer despegar al sector exportador, y afianzar a su país como potencia regional, al acercarse decididamente a la Asociación de Naciones del Sudeste de Asia (ANSEA, por sus siglas en inglés). Más tarde, al impulsar la formación de la Organización de Cooperación de Shanghái; China 
tomó la forma de un poder global, al diversificar sus acciones en lo institucional y en lo económico.

El ímpetu de China por buscar escapar del bloqueo occidental y por recomponer su imagen internacional propició el surgimiento de la "teoría de la amenaza china". Dicha "teoría" expresa que debido a su rápido crecimiento económico y sistema político autoritario, China representa una amenaza al orden internacional establecido y a la seguridad regional. ${ }^{28} \mathrm{Al}$ respecto, es importante precisar que este planteamiento presenta connotaciones diferenciadas para los países en desarrollo y los desarrollados. Para los primeros, como México y prácticamente todos los países latinoamericanos, la "amenaza china" se encuentra en asuntos comerciales y económicos. Para los segundos, en donde están, entre otros, Estados Unidos y la Unión Europea, involucra además asuntos de índole geopolítica.

La multidimensionalidad, entre otros componentes, se sustenta en un conjunto de ideas y acciones de considerable solidez. Ante ello, el gobierno chino empezó a trabajar en la formulación de estrategias de política exterior que le permitieran combatir la "teoría de la amenaza china" y ajustarse al nuevo orden internacional de principios de la década de 1990. Con ese fin, formularon variadas estrategias de política exterior ${ }^{29}$ y dieron un impulso sin precedentes a la diplomacia multilateral ${ }^{30} \mathrm{y}$ al establecimiento de "asociaciones" con diferentes países. ${ }^{31}$

A nivel global, la formación de "asociaciones" ha sido especialmente útil para combatir la teoría de la amenaza china y mejorar su

${ }^{28}$ Herbert Yee y Ian Storey, The China Threat: Perceptions, Myths and Reality, Nueva York, RoutledgeCurzon, 2002, p. 338.

${ }^{29}$ Por ejemplo, la "política de la periferia" o "del buen vecino", cuyo objetivo era mejorar sus relaciones con los países vecinos, particularmente con aquellos que no respaldaron la política del embargo económico.

30 Jianwei Wang, "China's Multilateral Diplomacy in the New Millennium”, en Yong Deng y Fei-ling Wang (eds.), China Rising: Power and Motivation in Chinese Foreign Policy, Maryland, Rowman \& Littlefield Publishers, Inc., 2005, pp. 159-200.

${ }^{31}$ You Ji y Jia Qingguo, “China's Re-emergence and Its Foreign Policy Strategy”, en Joseph Y.S. Cheng (ed.), China Review 1998, Hong Kong, The Chinese University Press, 1999, p. 152. 
imagen internacional, ya que con el establecimiento de dichas asociaciones se evita la formación de la idea de "competidor" o amenaza, favoreciendo la de "socio". ${ }^{32}$ Esta puede ser la razón por la que, desde sus inicios, el gobierno chino ha practicado esta política de forma generalizada, estableciendo "asociaciones" con países de todas las regiones y de diferentes niveles de desarrollo político, económico y social. A diferencia de la Unión Europea, que sólo tiene diez socios estratégicos, ${ }^{33}$ China cuenta con alrededor de 54 asociaciones, ${ }^{34}$ lo que sugiere que su interés principal es asociarse con el mayor número posible de países.

Esto se debe a que el gobierno chino, siguiendo la propuesta funcionalista, concede mayor importancia al elemento de "intereses comunes" al establecer una asociación, que a otros estándares, como valores afines, influencia internacional y fortaleza del país. Si éstos también fueran tomados en consideración, el gobierno chino tendría una red de asociaciones más estratégica, pero quizá no más funcional. ${ }^{35}$

En la discusión sobre la política exterior china, existe la idea de que la característica principal de las asociaciones chinas es que no responden a una estrategia o una política rígida o perfectamente delineada. Su fin es simplemente lograr socios, el porqué y para qué de la asociación puede o no existir. De hecho, "la simple aproximación para el establecimiento de una asociación con un tercero era considerado un éxito para el gobierno chino". ${ }^{36}$ Lo anterior puede explicar por qué los nombres y los procesos de

32 Oviedo, "China...", p. 401.

${ }^{33}$ Estados Unidos, China, Canadá, Japón, Brasil, Rusia, India, Sudáfrica, Corea del Sur y México.

34 Noticias del Partido Comunista Chino, “遍布全球的中国“伙伴矢系” [Las “asociaciones” de China cubren el mundo], 6 de junio de 2013, http://cpc. people.com.cn/n/2013/0606/c64387-21760090.html Es probable que China cuente con más asociaciones de las enumeradas en esta nota. Por ejemplo, en ella no se incluye la Asociación Estratégica integral establecida con Dinamarca en 2008, lo que nos hace pensar que quizá existan más casos de omisión como éste.

${ }^{35}$ Mao Weizhun, "Strategic Partnerships Need Common Values, Not Temporary Interests”, Global Times, 12 de diciembre de 2012, http:/ /www.globaltimes.cn/ content/749818.shtml

${ }^{36}$ Rocha Pino, "La simetría...", p. 137. 
desarrollo de las asociaciones tienden a divergir, y por qué, en la mayoría de los casos, se establecieron sin una definición clara y pública, sobre los elementos de la relación bilateral que propiciaron su creación y los objetivos específicos que persigue.

En el caso de México, primero se estableció una Asociación de Cooperación Integral (全面合作伙伴关系) en 1997, que fue elevada aunaAsociación Estratégica (战略伙伴矢系) en 2003y, recientemente a una Asociación Estratégica Integral (全面战略伙伴矢系), durante la visita de Xi Jinping en 2013. A su vez, otros países que también tienen una Asociación Estratégica Integral con China han alcanzado este nivel por medio de diferentes asociaciones preliminares. Por ejemplo, Francia pasó de una Asociación Integral a una Asociación Estratégica Integral, ${ }^{37}$ mientras que Dinamarca inició su asociación con China en este nivel. ${ }^{38}$

En términos de nombres, se puede decir que, aunque las denominaciones "asociación estratégica" y "asociación estratégica integral” son las más recurrentes, en muchos casos éstas reciben "apellidos" ad hoc. Algunos casos son los siguientes:

Rusia y China establecieron una Asociación Constructiva (建 设性伙伴矢系) en 1994, la cual fue elevada a una Asociación de Coordinación Estratégica (战略协作伙伴矢系) en 1996 y, por último, a una Asociación de Coordinación Estratégica Integral (全面 战略协作伙伴矢系) en 2012. ${ }^{39}$

- Por otro lado, Beijing y Delhi sostienen una Asociación de Cooperación Estratégica para la Paz y Prosperidad (面向和平与繁 荣的战略合作伙伴矢系) desde 2005. ${ }^{40}$

${ }^{37}$ Ministerio de Relaciones Exteriores de la República Popular China, “中国与 法国建立长期的全面伙伴矢系” [China y Francia establecen una Asociación Integral de largo periodo], http://www.fmprc.gov.cn/mfa_chn/ziliao_611306/wjs_611318/ 2159_611322/t8997.shtml

${ }^{38}$ People's Daily Online, "Chinese premier, Danish PM hold talks in Beijing”, http://english.peopledaily.com.cn/90001/90776/90883/6519682.html

39 Xinhua, “背景资料: 中国与俄罗斯矢系大事记” [Antecedentes: crónica de larelacióndeChinayRusia],http://news.xinhuanet.com/world/2013-03/21/c_11 5110738.htm

${ }^{40}$ Xinhua, "China, India to build strategic partnership", http:/ / news.xinhuanet.com/english/2005-04/12/content_2819423.htm 
Esto es un indicio más de que no hay una política definida para el nombre o el contenido de las asociaciones y que ambos aspectos tienden a variar, de acuerdo con el caso de que se trate. Goldstein establece que, a pesar de lo anterior, hay cuatro características compartidas por todas las asociaciones: ${ }^{41}$

1. No están dirigidas contra una tercera parte.

2. Promueven ampliamente los intercambios económicos.

3. Evitan desacuerdos sobre asuntos domésticos.

4. Fomentan frecuentes visitas oficiales.

En el contexto del funcionalismo, la descripción de estas asociaciones encaja con la de los arreglos funcionales que propone Mitrany, en los cuales recomienda que se realce la importancia de los vínculos económicos, haciendo a un lado aquellos elementos políticos o, como lo dice el tercer punto, "asuntos domésticos" que pueden llevar a desacuerdos.

\section{Las asociaciones de México y China}

Cuando los gobiernos chino y mexicano establecieron su primera asociación en 1997, China ya tenía una presencia importante en el continente americano. Desde 1990, sostenía un diálogo político con el Grupo de Río; en 1991 ingresó como observador al Banco Interamericano de Desarrollo (BID) y, en 1994, fue el primer país asiático en convertirse en miembro observador de la Asociación Latinoamericana de Integración (ALADI).

Ya desde esta época, los flujos comerciales entre China y México, aunque no se comparan con los de hoy, se caracterizaban por una creciente balanza comercial favorable a China, lo cual responde al mencionado despegue exportador de este país. De acuerdo con estadísticas de la Secretaría de Economía, entre 1993 y 1997, las exportaciones chinas a México se triplicaron, al pasar de 386.4 a 1247.3 millones de dólares. Si consideramos que durante este periodo México exportó a China poco más de 41 millones de dólares anuales en promedio, podemos calcular que la balanza comercial,

${ }^{41}$ Goldstein, "The Diplomatic...", p. 847. 
deficitaria para México y positiva para China, ascendió en 1997 a 1200 millones de dólares. ${ }^{42}$

Esta desproporción no pasó desapercibida por el gobierno mexicano y fue uno de los factores que propició que, en 1994, México se convirtiera en el primer país latinoamericano en imponer cuotas compensatorias a productos originarios de China. ${ }^{43}$ Con dicho acontecimiento como distintivo de la relación, a propuesta del gobierno chino, ambos socios acordaron establecer una Asociación de Cooperación Integral, el 1 de diciembre de 1997, durante la visita del presidente Jiang Zemin a México. ${ }^{44}$ Ésta era la segunda que China establecía con un país latinoamericano. La primera fue con Brasil en 1993.

Durante el anuncio de establecimiento, señalaron los siguientes cuatro puntos como las líneas fundamentales de la Asociación:

a) mantener y acrecentar el contacto político al más alto nivel, y, en la medida de lo posible, el de carácter personal entre los dirigentes políticos de ambos países;

b) intensificar, sobre la base de la reciprocidad, las relaciones económicas;

c) intensificar la cooperación bilateral;

d) mantener fluida la comunicación que existe entre los dos gobiernos para seguir trabajando conforme a los intereses y estrategias comunes en los foros internacionales y multilaterales. ${ }^{45}$

42 Secretaría de Economía, "Balanza Comercial de México con China”, http://200.77.231.38/sic_php/pages/estadisticas/mexicojun2011/Z3bc_e.html (consultada el 6 de enero de 2014).

${ }^{43}$ Romer Cornejo, "De la competencia diplomática a la competencia económica”, en Enrique Dussel (coord.), Cuarenta años de la relación entre México y China: acuerdos, desencuentros y futuro, México, unam, 2012, p. 270.

${ }^{44}$ Éste era el segundo presidente chino que visitaba México, el primero fue Yang Shangkun, en 1990.

${ }^{45}$ Presidencia de la República, "Versión estenográfica de las palabras del presidente Ernesto Zedillo, durante la Reunión Ampliada que encabezó, junto con el Excmo. señor Jiang Zemín, presidente de la República Popular de China, a la que asistieron también las comitivas de ambos países, en donde fueron suscritos Acuerdos y Convenios de cooperación bilateral, hoy en la mañana, en el salón Adolfo López Mateos de la residencia oficial de Los Pinos" (1 de diciembre de 1997), http://zedillo.presidencia.gob.mx/pages/disc/dic97/01dic97-1.html 
De acuerdo con estas líneas, se buscaba intensificar el contacto político y las relaciones económicas entre ambos gobiernos. No obstante, la ausencia de acciones concretas por medio de las cuales llevar a cabo dichos objetivos sugiere que el establecimiento de la asociación fue una medida de contención. Es decir, por medio de dicha medida, el gobierno chino trató de crear un discurso de cercanía con su contraparte mexicana, no para mejorar la relación, sino para evitar que empeorara y que los conflictos comerciales dañaran su imagen en América Latina, lo que hubiera significado la materialización de la "teoría de la amenaza china" en la región.

Esto nos lleva a plantear que dicha asociación ha podido ser un mecanismo funcionalista que, tal y como plantea Steele, se diseñó para atender un objetivo específico, bajo una circunstancia (tiempo) bien delimitada.

Tres años después del establecimiento de esta asociación, ocurrieron dos acontecimientos que han marcado y dificultado el desarrollo de la relación bilateral hasta nuestros días:

- El primero fue en 2001, con la culminación del proceso de ingreso de China a la omc en el que México se distinguió por el ser el último país en aceptarlo. ${ }^{46}$

- El segundo fue en 2003, cuando China desplazó a México como el segundo socio comercial de Estados Unidos.

Ante estos eventos, especialmente el primero, la Asociación de Cooperación Integral no fungió como un medio que facilitara el diálogo. Al contrario, se olvidó que se tenía una relación "especial”, de socios. Esto fue evidente cuando, en 2003, durante la visita a México del entonces primer ministro Wen Jiabao, el gobierno chino repitió la receta: ante un escenario de tensión en la relación bilateral y sin ninguna referencia a la asociación anterior, propuso el establecimiento de una nueva asociación, ahora bajo el nombre de "Asociación Estratégica". Esta asociación vino acompañada de

${ }^{46}$ La negociación entre China y México fue la última en concluir y fue un día hábil antes de que el Protocolo de Adhesión fuera a someterse a votación en el pleno del Grupo de Trabajo. Luis de la Calle, "China en la oмc. Espejo para México”, Foreign Affairs en español, vol. 2, núm. 3, otoño-invierno de 2002, pp. 152-161; y омc, "Cómo pasar a ser miembro de la omc", http:/ /www.wto.org/spanish/thew to_s/acc_s/acces_s.htm 
un mensaje mejor formulado, que ponía énfasis en que México y China eran "socios, no competidores", ${ }^{47}$ y que -ahora sí- incluía acciones específicas para incrementar la cooperación en materia económica:

1. Expandir el volumen y mejorar la estructura del comercio bilateral. En este punto, Wen enfatizó que China deseaba incrementar sus importaciones de México, pero que también esperaba que se facilitará la entrada de productos chinos al mercado mexicano.

2. Incrementar la inversión y expandir las áreas de cooperación. Aquí, Wen anunció que China estaba lista para trabajar en acuerdos para la protección de inversiones y para evitar la doble tributación.

3. Ampliar las relaciones entre los sectores empresariales y promover la comprensión mutua.

4. Buscar nuevos medios para lograr una cooperación mutuamente benéfica, tarea en la que la $11 .^{\text {a }}$ Reunión del Comité Conjunto China-México de Economía y Comercio debería concentrarse. ${ }^{48}$

A diferencia de la Asociación de Cooperación Integral de 1997, la cual no contó con medios de profundización, el establecimiento de la Asociación Estratégica en 2003 contempló la creación de una Comisión Binacional como el principal mecanismo institucional para dar contenido a esta Asociación. ${ }^{49}$ Dicha comisión se estableció formalmente en 2004, con la tarea de procurar y vigilar la profundización de la relación en lo general, por medio de acciones concretas que abarcaran desde aspectos comerciales hasta cooperación científica y cultural. ${ }^{50}$

Con ese fin, decidieron formular planes de trabajo para orientar el desarrollo de la relación. Estos planes, conocidos como "Pro-

${ }^{47}$ People's Daily Online, "Wen: China, Mexico are partners, not competitors", http:/ /english.peopledaily.com.cn/200312/14/eng20031214_130342.shtml

${ }^{48}$ Ibid.

49 Lourdes Aranda Bezaury, "México y China: una Asociación Estratégica", China Hoy, 2010, http://spanish.china.org.cn/specials/Mexico200/2010-09/13/ content_20920475.htm

50 A la fecha, se han realizado cinco (2004, 2006, 2008, 2010 y 2012) reuniones alternando la sede entre la ciudad de México y Beijing. En 2014, se llevará a cabo la sexta, en la ciudad de México. 
gramas de Acción Conjunta”, fueron acordados por los entonces presidentes Vicente Fox y Hu Jintao, en el marco de la visita de Estado que Hu realizó a México en septiembre de 2005. A la fecha, la Comisión Binacional ha adoptado dos Programas de Acción Conjunta, uno para el periodo 2006-2010 y otro para 2011-2015.

El establecimiento de la Comisión Binacional marcó el inicio de una extraordinaria institucionalización de la relación bilateral (véase el cuadro 3):

- En septiembre de 2003 se creó el Grupo de Trabajo de Alto Nivel México-China (GAN) entre la Secretaría de Economía y el Ministerio de Comercio de China, con la labor de sostener consultas bilaterales sobre todos los asuntos vinculados al comercio y las inversiones. Por lo tanto, quedó a cargo de algunos de los temas más importantes de la relación, como la negociación del Acuerdo para la Promoción y la Protección Recíproca de las Inversiones (APPRI) que se aprobó en 2008, las consultas relativas al otorgamiento del estatus de economía de mercado a China, las investigaciones de dumping y la cooperación en materia de estadísticas comerciales.

- Ya en el periodo de Calderón, durante su primer viaje a China en 2008, se acordó la creación del Diálogo Estratégico para tratar los temas sensibles de la relación y compartir posiciones sobre los principales temas y problemas globales. ${ }^{51} \mathrm{~A}$ la fecha, este mecanismo ha sostenido tres reuniones: la primera en agosto de 2009, en la ciudad de México, la segunda en Beijing, en 2011, y la tercera en octubre de 2013, en la ciudad de México.

- En 2010 fue creado el Foro Permanente de Diálogo Parlamentario entre el Congreso Mexicano y la Asamblea Popular Nacional de China, mecanismo de consulta para ofrecer continuidad a los acuerdos de la Comisión Binacional México-China, así como para complementar los canales diplomáticos habituales. ${ }^{52}$

${ }^{51}$ Ministerio de Relaciones Exteriores de la República Popular China, "Joint Press Communiqué between the People's Republic of China and the United Mexican States" (2008/07/12), http://www.fmprc.gov.cn/eng/wjdt/2649/t481164.htm

${ }^{52} \mathrm{Wu}$, Yongheng, "Apertura del Foro de Diálogo Parlamentario México-China”, China Hoy, http://www.chinatoday.com.cn/ctspanish/se/txt/2010-12/16/co ntent_319457.htm 


\section{Cuadro 3}

Mecanismos de diálogo y consulta creados a partir del establecimiento de la Asociación Estratégica en 2003 (2003-2010)

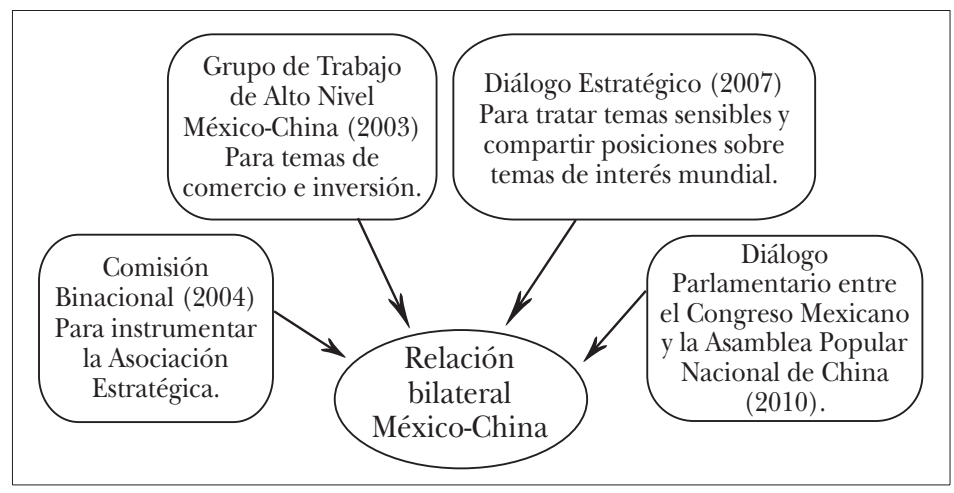

Fuente: Elaboración propia con base en Presidencia de la República, "Establecen China y México Comisión Binacional”, http://fox.presidencia.gob.mx/buena snoticias/?contenido=8897\&pagina=337; y SRE, "Nuevos espacios para México en Asia-Pacífico", http://www.sre.gob.mx/images/stories/doctransparencia/rdc/me modoc/3mddgap.pdf

La institucionalización que vivió la relación a partir del establecimiento de la Asociación Estratégica en 2003 es histórica y pareció, en teoría, crear los mecanismos suficientes para atender oportunamente las crisis y altibajos de la relación. No obstante, dos eventos mostraron los límites de dichos mecanismos y las debilidades de la Asociación.

Uno de ellos fue el episodio de críticas y molestias entre los gobiernos chino y mexicano, en el contexto de la epidemia de virus AH1N1 que se vivió en México durante 2009. Debido a dicha epidemia, un grupo de mexicanos fue puesto en cuarentena a su arribo a Beijing. Ante tal situación, y presionado por la forma en la que los medios de comunicación mexicanos lo magnificaron, Calderón comentó que, a diferencia de China durante la epidemia de sars en 2003, México había sido muy transparente y reportó del primero hasta el último de los casos. Esta declaración provocó, entre otras cosas, que el gobierno chino cerrara su 
Consulado en México durante dos semanas ${ }^{53}$ Con esa reacción se olvidaba el trato similar dado a ciudadanos chinos en suelo mexicano en otras ocasiones. ${ }^{54}$

El segundo evento fue la reunión del entonces presidente de México, Felipe Calderón, con el Dalái Lama en septiembre de 2011. En respuesta a dicho encuentro, el vocero del Ministerio de Asuntos Exteriores de China, Ma Zhaoxu, declaró que ésta "interfiere gravemente con los asuntos internos de China, ofende al pueblo chino y daña la relación México-China". Además, en un comunicado, "urge a la parte mexicana a tomar medidas concretas para remover el impacto negativo y mantener el sólido y estable desarrollo de las relaciones de China y México". ${ }^{55}$ De acuerdo a Zeng Gang, embajador de China en México entre julio de 2011 y agosto de 2013, éste fue el evento que retrasó el acuerdo que permitiría la exportación de carne de cerdo mexicana a China. ${ }^{56}$

Los eventos señalados muestran que los grandes avances realizados en materia de institucionalización de la relación no se lograron traducir en una mejora significativa de la comunicación entre ambos gobiernos. Al respecto, cabe agregar que, entre 2006 y 2012, México inició cuatro procedimientos de solución de diferencias contra China en la omc, y que participó en siete más de ellos, como "tercera parte", ${ }^{57}$ a pesar de que se cuenta con un Grupo de Trabajo de Alto Nivel para temas de comercio e inversión que, en teoría, debería evitar la llegada de estas diferencias a instancias

${ }^{53}$ Para mayor información sobre éste y otros eventos ocurridos en la relación China-México durante la administración de Calderón, véase Romer Cornejo, "La relación de México con China”, Foro Internacional, vol. 53, núms. 3-4, julio-diciembre de 2013, pp. 654-655.

54 Tema analizado en Romer Cornejo, F. J. Haro Navejas y J. L. León-Manríquez, "Trade Issues and Beyond: Mexican Perceptions on Contemporary China", Latin American Policy, vol. 4, núm.1, 2013, pp. 57-75.

${ }_{55} \mathrm{El}$ contenido completo del comunicado puede consultarse en: http:// www.fmprc.gov.cn/eng/xwfw/s2510/2535/t858835.shtml

56 "Reunión de FCH con Dalái Lama dañó relación México-China: Zeng Gang”, Excélsior, 2 de junio de 2013, http:/ / www.excelsior.com.mx/nacional/2013 /06/02/902110

${ }^{57}$ OMC, "Diferencias por país/territorio", http://www.wto.org/spanish/tratop _s/dispu_s/dispu_by_country_s.htm (consultado 13 de enero de 2014). 
multilaterales. Esto alienta a crear la percepción de que se sigue la agenda estadounidense en materia comercial y que estos mecanismos funcionalistas no han logrado el efecto spillover de la cooperación económica hacia temas politizados, como las acusaciones de comercio desleal.

Debido a los eventos descritos, el nuevo gobierno de México, que tomó posesión en diciembre de 2012, recibió la relación con China en una situación tensa y distante, a la que varios especialistas calificaron como "la peor en su historia". 58

Las primeras medidas que tomó el gobierno de Enrique Peña Nieto, ya mencionadas, propiciaron una rápida visita de Estado del presidente chino, Xi Jinping, como parte de una gira iniciada en el Caribe y finalizada en Estados Unidos. Como lo hemos comentado, durante dicha visita, se anunció el cambio de nivel de las relaciones bilaterales, de una Asociación Estratégica a una Asociación Estratégica Integral, repitiendo así el patrón de establecer una presunta nueva asociación después de que la relación ha pasado por un periodo de tensión.

A diferencia de los casos anteriores (1997 y 2003), en esta ocasión fue México el primero en dar el paso hacia la normalización de las relaciones, aspecto en el que pudo haber influido la personalidad y experiencia del presidente Peña Nieto. En este sentido, cabe mencionar que desde su periodo como gobernador del Estado de México (2005-2011), Peña Nieto mostró un interés particular en China. Durante su mandato visitó China en dos ocasiones: la primera en noviembre de 2007, como parte de una gira de trabajo por Asia, que también incluyó Corea y Japón; y la segunda en noviembre de 2010, en una visita exclusiva a China.

En ambas visitas, Peña Nieto insistió en buscar los medios para incrementar los intercambios comerciales entre el Estado de México y China, especialmente para atraer inversiones hacia los proyectos de infraestructura de su entidad. Destaca que, durante su segundo viaje, enfatizó en la necesidad de lograr que México se

58 Véase Cornejo, "La relación...", p. 655; y Enrique Dussel Peters, "ChinaMéxico, ¿hoy?”, Reforma, sección Negocios, 20 de noviembre de 2012, p. 4. 
ubicara en "el centro de las opciones de China" 59 y en "aprovechar su dinámica económica”, particularmente a través de la riqueza turística mexicana. ${ }^{60}$

Antes de llegar a la presidencia de México, Peña Nieto ratificó la importancia que concedía a la relación con China en su libro México, la gran esperanza. En él señala que las relaciones bilaterales más significativas de México son las que se tienen con Estados Unidos y China, ya que éstos constituyen un G2 de facto: "la capacidad de México para posicionarse como un país líder entre economías emergentes y con capacidad de interlocución con el mundo desarrollado dependerá en gran medida de sus relaciones bilaterales con Estados Unidos y China”. ${ }^{61}$

Para conducir la relación con China, Peña Nieto propuso que "México debe diferenciarse y dejar de competir con China a través de la incorporación de mayor valor científico y tecnológico a nuestros productos y servicios". ${ }^{62}$ Las ideas mencionadas representan un cambio discursivo significativo respecto a la forma en que se había conducido la relación con Beijing, pues reconoce que este país tiene un peso similar al de Estados Unidos -con todo lo que eso implicaría para México-, y propone convertirse en su socio.

El interés gubernamental mexicano ha sido bien recibido y correspondido por el presidente Xi. Éste atendió rápidamente la invitación a viajar a México, que se convirtió en la primera visita de Estado que recibió Peña Nieto como presidente. Además, durante la Cumbre del G20, en San Petersburgo, Xi ofreció a Peña Nieto una cena de Estado. ${ }^{63}$

${ }^{59}$ Gobierno del Estado de México, "Necesitamos ubicar a México en el centro de las opciones de China: Peña Nieto", http://www.gem.gob.mx/medios/ w2comp.asp?Folio_=16165

${ }^{60}$ Gobierno del Estado de México, "Necesitamos ubicar a México en el centro de las opciones de China: Peña Nieto”, http://www.gem.gob.mx/medios/ w2comp.asp?Folio_=16165

${ }^{61}$ Enrique Peña Nieto, México, la gran esperanza: Un Estado eficaz para una democracia de resultados, México, Grijalbo, 2011, p. 159.

${ }^{62}$ Ibid., p.158.

${ }^{63}$ Presidencia de la República, "Se reúnen los presidentes de México, Enrique 
Respecto a la nueva asociación con China, como cabría esperar según explicamos antes, no hay una definición concreta sobre sus objetivos. El anuncio de su establecimiento no vino acompañado de declaraciones o información alguna que nos diera pistas sobre cuál es la diferencia entre una Asociación Estratégica y una Asociación Estratégica Integral, cuáles son las ventajas de esta última y las razones por las cuales se ha realizado dicho cambio.

$\mathrm{Al}$ respecto, la Declaración Conjunta, que es el único documento en el que ambas naciones se refieren a todos los acuerdos y decisiones tomadas durante la visita de Xi a México, plantea la nueva Asociación Estratégica Integral en los siguientes términos:

a) "Imprimirá un renovado impulso" para que las relaciones bilaterales "entren en una nueva etapa de desarrollo".

b) "Estará anclada en un diálogo político fluido e intenso" respecto a temas "bilaterales, regionales y globales".

c) Los dirigentes de ambos gobiernos se encontrarán frecuentemente "en el marco de su participación en reuniones y foros internacionales".

d) Fortalecerán la Comisión Binacional Permanente MéxicoChina.

e) En el marco del nuevo marco institucional de diálogo facilitado por la Asociación Estratégica Integral, ambos jefes del Ejecutivo "reconocieron la importancia de promover la participación del Poder Legislativo y otros niveles de gobierno, así como de la sociedad en su conjunto". ${ }^{64}$

Los objetivos son amplios y abiertos a la interpretación. Son más similares a aquéllos con los que se estableció la asociación de 1997, que a los de la asociación de 2003, los cuales fueron mucho más específicos. No obstante, la Asociación Estratégica Integral ya ha impulsado acciones concretas: el inicio de la exportación de tequila (agosto de 2013), ${ }^{65}$ el acuerdo para la exportación de car-

Peña Nieto y de China, Xi Jinping, por tercera ocasión”, http://www.presidencia. gob.mx/articulos-prensa/se-reunen-los-presidentes-de-mexico-enrique-pena-nieto-y-de-china-xi-jinping-por-tercera-ocasion/

${ }^{64} \mathrm{El}$ texto completo de dicha Declaración puede consultarse en: http:/ /www. eluniversal.com.mx/graficos/pdf13/declaracion-conjunta-mexico-china.pdf, p. 1-2. ${ }^{65}$ SAGARPA, "Inicia México exportación de tequila $100 \%$ agave a la Repúbli- 
ne de cerdo (la cual en 2014 se seguía esperando iniciara), la aprobación preliminar de una línea de crédito por 500 millones de dólares del Export-Import Bank de China al Banco Nacional de Comercio Exterior de México, y el establecimiento de tres nuevos mecanismos: un Grupo de Alto Nivel Empresarial (que sostuvo su primera reunión en noviembre de 2013), ${ }^{66}$ una unidad especializada en asuntos económicos en la Embajada de México en China y un Grupo de Trabajo de Alto Nivel en materia de Inversión.

Atomización de ACTORES Y RECURSOS NATURALES:

LA DEBILIDAD DE LO FUNCIONAL

Desde el inicio del establecimiento de las relaciones bilaterales en 1972, el principal actor de la relación entre México y China ha sido el Estado en ambos países. De manera más precisa, durante la mayor parte del tiempo, algunos de sus componentes, principalmente los gobiernos y algunas empresas paraestatales, han estado a cargo del funcionamiento de las interacciones sino-mexicanas. Sin embargo, el panorama se ha transformado de forma proporcional a los cambios sufridos en sus respectivas economías, producto de las políticas estatales y de los cambios globales.

En los dos países han cambiado los grupos sociales apoyados por sus respectivos Estados. La transformación ha obedecido a la apertura al mercado mundial, proceso que ha seguido diferentes ritmos y ha creado-apoyado a diferentes actores de acuerdo a las orientaciones específicas de las economías locales. Los Estados siguen siendo importantes y fuertes relativamente, sobre todo en el caso chino, pero existe una atomización de los actores de ambas naciones que juegan en el plano internacional. Además, el funcionalismo bilateral es disparejo en por lo menos tres sectores, dos de

\footnotetext{
ca Popular China”, http://www.sagarpa.gob.mx/saladeprensa/2012/Paginas/201 3B508.aspx

${ }^{66}$ Secretaría de Economía, "México y China fortalecen diálogo empresarial”, http:/ /www.economia.gob.mx/eventos-noticias/informacion-relevante/9994-pie2 91113
} 
ellos ligados a los recursos naturales y uno más a la manufactura: petróleo, minería e industria del calzado.

El caso del calzado es el más emblemático del funcionalismo asimétrico que persiste en la relación. El complejo entramado institucional construido por las diferentes asociaciones sino-mexicanas no ha ofrecido alternativas de cómo tratar con este tema. Si bien es cierto que, a principios de 2012, la Secretaría de Economía anunció el establecimiento de un acuerdo con el Ministerio de Comercio de China para monitorear en aduana los precios del calzado chino que ingresara al país, ${ }^{67}$ los zapateros mexicanos alegan que éste no ha funcionado. ${ }^{68}$

En este contexto, durante los primeros meses de 2014 diferentes organizaciones relacionadas al sector zapatero, entre las que destaca la Cámara de la Industria del Calzado del Estado de Guanajuato, han intensificado la presión hacia el gobierno mexicano, la cual ha operado a la par de una campaña anónima contra el consumo de calzado chino en la ciudad de León, que ha incluido la pinta de bardas con leyendas como "lo chino es chafa" y la distribución de volantes que advierten: "No dejes que China te quite tu chamba, hagamos algo ahora o nuestras familias pagarán el pato”. ${ }^{69}$

En la minería también es posible encontrar varios aspectos importantes de la debilidad de la relación y del fenómeno que hemos denominado atomización de los actores. En términos funcionalistas, el minero es un sector con grandes dificultades: el andamiaje institucional es prácticamente inexistente y el peso de los actores no gubernamentales es considerable, pero sobre todo los gobiernos no tienen control de ellos. Lo cual es más patente en México,

${ }^{67}$ Secretaría de Economía, "Acuerdan México y China condiciones que regirán las importaciones de calzado proveniente de ese país”, Comunicado de prensa núm. 090/12, León, Gto., a 27 de marzo de 2012, http://www.economia.gob.mx/ eventos-noticias/sala-de-prensa/comunicados/7655-bol-09012

${ }^{68}$ Isabel Becerril, "México prepara cuota compensatoria para los zapatos chinos", El Financiero, 27 de marzo de 2014, http:/ / www.elfinanciero.com.mx/econo$\mathrm{mia} /$ mexico-prepara-cuota-compensatoria-para-los-zapatos-chinos.html

69 Jonathan Juárez, "Combaten calzado de China”, Periódico AM, 25 de marzo de 2014, http://www.am.com.mx/leon/local/combaten-calzado-de-china-95438. html (14 de mayo de 2014). 
donde los diferentes niveles de gobierno se encuentran desarticulados y la atomización ha significado que los interesados en obtener ganancias en la minería realicen acciones ilegales sin ser criminales en todas sus actividades (presumiblemente algunos ciudadanos chinos) o que sean francamente criminales (en el caso presumible de algunos mexicanos). Fue hasta la visita de Xi, junio de 2013, que se firmó un Memorándum de Entendimiento sobre la Cooperación en Materia Minera.

Pese a que México no es el país más atractivo para la inversión china, ésta llega de manera directa e indirecta, mediante negociaciones con empresas canadienses o hasta comprando algunas de ellas. ${ }^{70}$ Como si nunca hubiera pasado, en diferentes momentos de los primeros meses de 2014, en varios medios aparecieron noticias sobre el contrabando de minerales extraídos en las montañas de Michoacán con destino a China. Inicialmente, pretendían salir desde el puerto Lázaro Cárdenas de ese Estado. Posteriormente, el contrabando fue incluso con algún barco de bandera panameña y tratando de zarpar desde Manzanillo, Colima. Es precisamente en esa entidad donde empresarios chinos han trabajado sin grandes problemas y de manera directa con actores locales no criminales a quienes les pagan por lo menos la mitad de lo que cuesta el mineral en el mercado argumentando que desean ayudar y que lo hacen de buena fe. El mineral llega al puerto y lo exportan a China mediante diferentes compañías, sin necesidad aparente de recurrir a actos ilegales, lo cual en ocasiones hacen en el punto de origen, aprovechando la ausencia de un adecuado funcionamiento institucional y de la atomización de los actores.

Hasta antes de la firma del primer contrato entre Pemex y la empresa china Unipec para la exportación de petróleo mexicano a China, el energético era el sector que mejor representaba la disfuncionalidad de la supuesta asociación estratégica sino-mexicana. Hoy, aún es posible resaltar algunos aspectos que diferencian

${ }^{70}$ Francisco Javier Haro Navejas y Gabriela Correa López, "Empresas e inversión de la República Popular China en México”, en Carlos Moneta y Sergio Cesarín (eds.), Tejiendo redes: estrategias de las empresas transnacionales asiáticas en América Latina, Buenos Aires, Universidad Nacional de Tres de Febrero, 2012, pp. 399-424. 
a ambos gobiernos, pero también algunos que dan funcionalidad a la relación en este ámbito.

En ambos países, partes de la maquinaria estatal siguen siendo la base de las políticas económicas y alientan el fortalecimiento de grupos económicos independientes. Aunque aparentemente el gobierno chino es más abierto que el mexicano en este campo, lo que los diferencia es la mundialización de las acciones chinas, el papel activo de Beijing y la utilización del sector como eje del crecimiento económico bajo dirección gubernamental central. Al igual que en otros aspectos, Zhongnanhai ${ }^{71}$ está bajo el control del proceso general, al contrario de México, donde el gobierno busca deshacerse de responsabilidades esenciales.

Durante la visita de Peña Nieto a China en 2013, se firmaron documentos importantes al respecto: el ya mencionado contrato entre Pemex y Unipec, subsidiaria de sinopec, para impulsar la exportación de petróleo de México a China; un memorándum de entendimiento entre PEMEx y Xinxing Cathay International Group Co. Ltd., con el fin de explorar la cooperación estratégica y establecer un marco para el posible intercambio de conocimiento técnico, experiencias y prácticas; y un memorándum de entendimiento entre Pemex y China National Petroleum Company (CNPC) para establecer un marco de cooperación que permita complementar los mercados e intercambiar experiencias y tecnología.

Desde una perspectiva funcionalista, en el ámbito petrolero los actores gubernamentales están creando bilateralmente los mecanismos que facilitarán el incremento de los intercambios y disminuirán sus costos, los cuales podrían profundizarse a partir de las reformas institucionales internas en el país oferente de recursos naturales y necesitado de inversión. El gobierno mexicano ha optado por el camino de la reforma energética para atraer inversión presumiblemente para mediados de 2015 y para lo que las empresas chinas parecen estar listas. Desde esa misma perspectiva, observamos que la intervención de los actores se está desarrollando de manera ordenada y legal. A diferencia de lo que está ocurriendo en los sectores del calzado y la minería, los cuales, a pesar

${ }^{71}$ Sede oficial del gobierno de la República Popular China. 
de su relevancia y alta presencia en medios, parecen no encontrar un lugar en la agenda bilateral.

\section{EL VIAJE INCONCLUSO Y LA ASOCIACIÓN INCOMPLETA}

Para concluir, es preciso hacer dos comentarios teóricos metodológicos. Primero, desde una perspectiva teórica, y al igual que "[c]ualquier teoría comprobable de negociación internacional", un enfoque funcionalista "debe estar enraizado en una teoría de política doméstica”. ${ }^{72}$ Es decir, la comprensión cabal de los temas tratados en estas páginas y su solución dependen de la formulación de estrategias de acción viables y concretas; de lo contrario, el trato con actores chinos seguirá dominado por el culturalismo y el voluntarismo del gobierno en turno.

Segundo, de forma empírica y gracias tanto al proceso de socialización política en los organismos internacionales como a las experiencias propias de cuatro décadas de relaciones bilaterales, Beijing y México han levantado un orden funcional con severas limitaciones, que no ha logrado avanzar hacia temas políticamente complejos, pero que ha sentado las bases para un futuro desparramamiento o spillover de la agenda.

No obstante lo relativamente apabullante del déficit que México mantiene en su comercio con China, el dilema no es acerca de cantidades o de productos. El reto funcionalista es fortalecer el ámbito institucional para crear certidumbre, predictibilidad, legalidad y disminución de costos en beneficio de los actores, cada vez más atomizados. Más que un tratado de libre comercio con China, políticamente imposible de plantear, los acuerdos específicos, como los logrados hasta ahora, permitirán fortalecer la cooperación e incrementar el comercio.

Damos por descontadas la competencia y la posibilidad, a corto o mediano plazos, de revertir la situación existente en el comercio bilateral. Los cambios que disminuyan la asimetría existente

72 Robert D. Putnam, "Diplomacy and Domestic Politics: The Logic of TwoLevel Games”, International Organization, vol. 42, núm. 3, 1988, p. 442. 
dependerán del fortalecimiento de una relación funcional, con mecanismos que "respondan a las necesidades y requerimientos de asuntos específicos alrededor de los cuales individuos y grupos puedan organizar sus actividades". ${ }^{73}$ Para lograr que estos mecanismos funcionen, la relación tendría que estar sustentada en una postura interna definida y una estrategia clara, pero también en sacar la negociación de la victimización y de buscar acercamiento a otros gobiernos, diferentes al de Estados Unidos, para negociar en mejor condiciones con gobierno y empresarios chinos. La reunión que sostuvieron en septiembre de 2014 los Ministros de la Alianza del Pacífico con ASEAn parece un buen inicio. ${ }^{74}$

El nuevo auge por la institucionalización que propició la visita de Xi, muestra que existe voluntad política de parte de ambos gobiernos. Sin embargo, no es garantía de mejor comunicación, particularmente frente a controversias. Como lo vimos durante el sexenio de Calderón, ninguno de los mecanismos que impulsó la Asociación Estratégica de 2003 fue capaz de evitar o contribuir a destensar la relación tras los episodios de molestia durante la crisis de influenza en México (2009), así como por la reunión de Calderón y el Dalái Lama (2011). Hoy los mecanismos son más; a la fecha, se cuenta con siete (véase el cuadro 4), pero no por ello podemos esperar que alguno de éstos ejerza funciones paras las que no fue diseñado.

Las asociaciones sino-mexicanas han representado un medio a través del cual el gobierno chino muestra interés y voluntad política para trabajar en el desarrollo de la relación bilateral. Sin embargo, no significan nada más que eso. Que sean "socios estratégicos" no significa que México vaya a recibir un trato especial o siquiera que exista voluntad para resolver las áreas de tensión de la relación, como ha sido el caso de la industria del calzado y, recientemente, el de minería, sectores que, lejos de entrar en la dinámica institucional, se polarizan y atomizan cada vez más.

73 Steele, "Revisiting Classical Functional Theory", p. 19.

${ }^{74}$ SRE, "Ministros de la Alianza del Pacífico y de la Asociación de Naciones del Sudeste Asiático (ANSEA) se reunieron en Nueva York", Comunicado Conjunto SRE-SE, viernes 26 de septiembre de 2014, México, D. F., http://saladeprensa.sre. gob.mx/index.php/es/comunicados/4940-429 


\section{Cuadro 4}

Nuevos mecanismos creados a partir del establecimiento de la Asociación Estratégica Integral (2013)

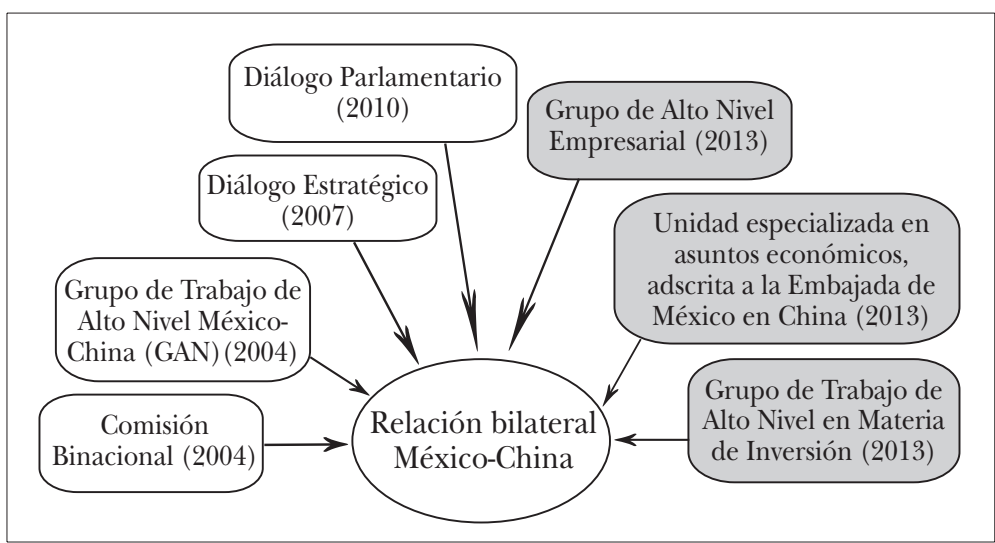

Fuente: Elaboración propia con base en Presidencia de la República, "Establecen...”; SRE, "Nuevos espacios...” y Presidencia de la República, Primer Informe de Gobierno 2012-2013, pp. 706-707.

Las asociaciones que se dan entre países asimétricos, como es el caso de México y China, tienden a favorecer al país con mayor poder. Una "asociación" que es aparentemente sólo un elemento retórico que complementa un discurso diplomático puede llegar a convertirse en un "caballo de Troya terminológico", 75 a través del cual la parte con mayor peso puede introducir condiciones o exigencias especiales a la "parte débil".

Considerando el interés del gobierno chino por ofrecer a México una nueva asociación cada vez que la relación experimentó dificultades, es posible afirmar que China ha empleado esta estrategia como un recurso funcionalista para mostrar voluntad de cooperación en asuntos bien delimitados y que, en la mayoría de los casos, conciernen a temas puramente económicos.

En razón de lo anterior, la Asociación Estratégica Integral con China puede significar nada y no generar impactos positivos en la

${ }^{75}$ Rocha Pino, “La simetría...”, p. 120. 
relación (como el caso de las primeras dos) o puede convertirse en un sistema de cooperación eficaz, que permita a ambos participantes obtener beneficios tangibles alrededor de acuerdos funcionales. La responsabilidad de que eso ocurra depende del gobierno mexicano. Desde la perspectiva del chino, y como si se tratara de una partida de ajedrez, ellos ya han hecho su movimiento y el reloj está en marcha.

\section{Bibliografía}

Anderson, Jennifer, The Limits of the Sino-Russian Strategic Partnership, Adelphi Paper 315, Nueva York, Oxford University Press, 1997.

Aranda Bezaury, Lourdes, "México y China: una Asociación Estratégica", China Hoy, 2010, http://spanish.china.org.cn/specials/Mexico200/ 2010-09/13/content_20920475.htm (consultado el 9 de enero de 2014).

Becerril, Isabel, "México prepara cuota compensatoria para los zapatos chinos", El Financiero, 27 de marzo de 2014, http:/ /www.elfinanciero. com.mx/economia/mexico-prepara-cuota-compensatoria-para-loszapatos-chinos.html (consultado el 14 de mayo de 2014).

Brown, Chris y Kirsten Ainley, Understanding International Relations, $3^{\mathrm{a}}$ ed., Nueva York, Palgrave, 2005.

Cornejo, Romer, "La relación de México con China", Foro Internacional, vol. 53, núms. 3-4, julio-diciembre de 2013, pp. 645-667.

, "De la competencia diplomática a la competencia económica", en Enrique Dussel (coord.), Cuarenta años de la relación entre México y China: acuerdos, desencuentros y futuro, México, unam, 2012.

— - "México y China: diplomacia, competencia económica y percepciones", en Foro Internacional, vol. 48, núm. 1-2, enero-junio de 2008, pp. 330-351.

Cornejo, Romer, F. J. Haro Navejas y J. L. León-Manríquez, "Trade Issues and Beyond: Mexican Perceptions on Contemporary China", Latin American Policy, vol. 4, núm.1, 2013, pp. 57-75.

Cortés, Maricarmen, "China, ¿de temible competidor a socio ideal?, Excélsior, 6 de junio de 2013, p. 6.

Covarrubias, Ana, "La política exterior 'activa'... una vez más", Foro Internacional, vol. 48, núms. 191-192, 2008. 
Cox, Robert W., "Social Forces, States and World Orders: Beyond International Relations Theory", en Robert O. Keohane (coord.), Neorealism and Its Critics, Nueva York, Columbia University Press, 1986, pp. 204-253.

Chen, Yuanting, "China y México, ¿socios rivales?”, China Hoy, 1 de marzo de 2012, http://www.chinatoday.mx/eco/clae/content/2012-03/ 01/content_429288.htm (consultado el 14 de abril de 2013).

De la Calle, Luis, "China en la oмc. Espejo para México", Foreign Affairs en español, vol. 2, núm. 3, otoño-invierno de 2002, pp. 152-161.

De Vega, Mercedes (coord.), Historia de las relaciones internacionales de México, 1821-2010, Volumen 6: Asia, México, Secretaría de Relaciones Exteriores, 2011.

Deng, Yong, "Remolding great power politics: China's strategic partnerships with Russia, the European Union, and India”, Journal of Strategic Studies, vol. 30, núms. 4-5, 2007, pp. 863-903.

DOF, Plan Nacional de Desarrollo 1983-1988, http://dof.gob.mx/nota_detalle.php?codigo $=4805999 \&$ fecha $=31 / 05 / 1983$ (consultado el 24 de octubre de 2013).

- Plan Nacional de Desarrollo 1995-2000, http:/ / dof.gob.mx/nota_ detalle.php?codigo $=4874791 \&$ fecha $=31 / 05 / 1995$

, Plan Nacional de Desarrollo 2001-2006, http://www.dof.gob.mx/ nota_detalle.php?codigo=766335\&fecha=30/05/2001 (consultado el 24 de octubre de 2013).

, Plan Nacional de Desarrollo 2007-2012, http:/ / www.dof.gob.mx/ nota_detalle.php?codigo $=4989401 \&$ fecha $=31 / 05 / 2007$ (consultado el 24 de octubre de 2013).

- Plan Nacional de Desarrollo 2013-2018, http:/ / www.dof.gob.mx/ nota_detalle.php?codigo=5299465\&fecha=20/05/2013

Dussel, Enrique (coord.), Cuarenta años de la relación entre México y China: acuerdos, desencuentros y futuro, México, UNAM, 2012.

—, "China-México, ¿hoy?”, Reforma, sección Negocios, 20 de noviembre de 2012, http:/ / dusselpeters.com/reforma2012-10.pdf (consultado el 14 de febrero de 2014).

El Colegio de México, "Segundo congreso internacional sobre la enseñanza del chino" [archivo de video], Intervención del Embajador Qiu Xiaoqi [min.4.30], YouTube, 12 de marzo de 2014, https://www.youtube.com/watch?v=6U0ggvLgjTc\&list=PLhIF5xewDHRxP1DKdN7H S2pRhCZe_gWUX\&index=4 (consultado el 10 de julio de 2014). 
El Universal, "Declaración Conjunta México-China", http://www.eluniversal.com.mx/graficos/pdf13/declaracion-conjunta-mexico-china.pdf (consultado el 7 de junio de 2013).

Franco Hijuelos, Claudia, "La Asociación Estratégica México-Unión Europea: origen y perspectivas", Revista Mexicana de Política Exterior, núm. 89, marzo-junio de 2010, pp. 57-82.

Garduño, Silvia, "Celebra Congreso relación con China", Reforma, 6 de junio de 2013, p. 5.

Gobierno del Estado de México, "Necesitamos ubicar a México en el centro de las opciones de China: Peña Nieto”, http://www.gem.gob.mx/ medios/w2comp.asp?Folio_=16165

-, "México necesita aprovechar la dinámica económica global de China: Peña Nieto”, http://www.gem.gob.mx/medios/w2comp. asp?Folio_ $=16166$

Goldstein, Avery, "The Diplomatic Face of China's Grand Strategy: A Rising Power's Emerging Choice", The China Quarterly, núm. 168, diciembre de 2001.

Haro, Francisco Javier, Religión y ciencia en las relaciones internacionales: $E l$ discurso en los intercambios gubernamentales sino-mexicanos, Inter-Asia Paper, núm. 24, 2011, Universidad Autónoma de Barcelona, versión electrónica en https://ddd.uab.cat/pub/intasipap/intasipap_ a2011n24/intasipap_a2011n24p1.pdf (consultado el 4 de marzo de 2014).

- y Gabriela Correa López, "Empresas e inversión de la República Popular China en México”, en Carlos Moneta y Sergio Cesarín (eds.), Tejiendo redes: estrategias de las empresas transnacionales asiáticas en América Latina, Buenos Aires, Universidad Nacional de Tres de Febrero, 2012, pp. 399-424.

Jerdén, Björn y Linus Hagström, "Rethinking Japan’s China policy: Japan as an Accommodator in the Rise of China, 1978-2011", Journal of East Asian Studies, vol. 12, núm. 2, 2012, pp. 215-250.

Juárez, Jonathan "Combaten calzado de China”, Periódico AM, 25 de marzo de 2014, http://www.am.com.mx/leon/local/combaten-calzadode-china-95438.html (14 de mayo de 2014).

Li Chenyang, "China-Myanmar Comprehensive Strategic Cooperative Partnership: A Regional Threat?", Journal of Current Southeast Asian Affairs, vol. 31, núm. 1, 2012, pp. 53-72. 
Lo Bobo, "The Long Sunset of Strategic Partnership: Russia's Evolving China Policy", International Affairs, vol. 80, núm. 2, marzo de 2004, pp. 295-309.

Mao Weizhun, "Strategic partnerships need common values, not temporary interests”, Global Times, 12 de diciembre de 2012, http://www. globaltimes.cn/content/749818.shtml

Méndez, Ernesto, "Fox cabildea proyecto turístico por el que temen catástrofe ambiental”, Excélsior (en línea), 21 de mayo de 2014, http:// www.excelsior.com.mx/nacional/2014/05/21/960495

Ministerio de Relaciones Exteriores de la República Popular China, "Reunión Informativa Ofrecida por Funcionarios del Ministerio de Relaciones Exteriores sobre la visita del Primer Ministro Wen Jiabao a los Estados Unidos, Canadá, México y Etiopía y su Asistencia a la II Conferencia Ministerial del Foro de Cooperación Sino-Africana" (2003/11/27), http://www.mfa.gov.cn/esp/zt/wjbzlzf/wenjiabaovisitspain/t50543.shtml

- "Foreign Ministry Spokesperson Ma Zhaoxu's Remarks on Mexican President Calderón's Meeting with Dalai (2011/09/10), http://www.fmprc.gov.cn/eng/xwfw/s2510/2535/t858835.shtml

一, “中国与法国建立长期的全面伙伴关系” (China y Francia establecen una Asociación Integral de largo periodo), http:/ /www.fmpr c.gov.cn/mfa_chn/ziliao_611306/wjs_611318/2159_611322/t8997. shtml (consultado el 28 de octubre de 2013).

-, "Joint Press Communiqué between the People's Republic of China and the United Mexican States" (2008/07/12), http://www. fmprc.gov.cn/eng/wjdt/2649/t481164.htm

- "Xi Jinping Holds Talks with President Nicolás Maduro of Venezuela Two Heads of State Announce to Promote China-Venezuela Relations to Comprehensive Strategic Partnership" (2014/07/21), http:/ / www.fmprc.gov.cn/mfa_eng/topics_665678/xjpzxcxjzgjldrdlchwdbxagtwnrlgbjxgsfwbcxzlldrhw/t1177107.shtml

, "Xi Jinping Holds Talks with President Cristina Fernández de Kirchner of Argentina and Two Heads of State Announce the Establishment of China-Argentina Comprehensive Strategic Partnership" (2014/07/19), http://www.fmprc.gov.cn/mfa_eng/zxxx_662805/ t1176630.shtml 
Mitrany, David, "The Functional Approach to World Organization", International Affairs, vol. 24, núm. 3, 1948, pp. 350-363.

Noticias del Partido Comunista Chino, “遍布全球的中国“伙伴关系” [Las "asociaciones" de China cubren el mundo"], 6 de junio de 2013, http://cpc.people.com.cn/n/2013/0606/c64387-21760090.html (consultado el 28 de octubre de 2013).

omc, "Cómo pasar a ser miembro de la omc", http://www.wto.org/ spanish/thewto_s/acc_s/acces_s.htm

, "Diferencias por país/territorio", http://www.wto.org/spanish/tratop_s/dispu_s/dispu_by_country_s.htm

Oviedo, Eduardo Daniel, "China: visión y práctica de sus llamadas relaciones estratégicas”, Estudios de Asia y África, vol. 41, núm. 3, septiembrediciembre de 2006.

Orden Jurídico, Plan Nacional de Desarrollo 1989-1994, http:/ / ordenjuridico.gob.mx/Publicaciones/CDs2011/CDPaneacionD/pdf/PND\%20 1989-1994.pdf

Pemex, "PEMEx suscribe importantes acuerdos en China", http://www. pemex.com/prensa/boletines_nacionales/Paginas/08042013. aspx\#.UuKqMtK3UdU (consultado el 24 de enero de 2014).

Peña Nieto, Enrique, México, la gran esperanza: Un Estado eficaz para una democracia de resultados, México, Grijalbo, 2011.

People's Daily Online, "Wen: China, Mexico Are Partners, Not Competitors", http://english.peopledaily.com.cn/200312/14/eng20031214_ 130342.shtml (consultado el 9 de enero de 2014).

_-, "Chinese premier, Danish PM hold talks in Beijing", http:// english.peopledaily.com.cn/90001/90776/90883/6519682.html

Prados, Luis, "Xi Jinping y Peña Nieto firman el 'pacto del tequila”, $E l$ Pais, 5 de junio de 2013, http://internacional.elpais.com/internacional/2013/06/05/actualidad/1370398104_078536.html

Presidencia de la República, "Versión estenográfica de las palabras del presidente Ernesto Zedillo, durante la Reunión Ampliada que encabezó, junto con el Excmo. señor Jiang Zemín, presidente de la República Popular de China, a la que asistieron también las comitivas de ambos países, en donde fueron suscritos Acuerdos y Convenios de cooperación bilateral, hoy en la mañana, en el salón Adolfo López Mateos de la residencia oficial de Los Pinos" (1 de diciembre de 
1997), http://zedillo.presidencia.gob.mx/pages/disc/dic97/01dic9 7-1.html (consultado el 27 de septiembre de 2013).

, "Establecen China y México Comisión Binacional", http:/ / fox. presidencia.gob.mx/buenasnoticias/?contenido=8897\&pagina=337 (consultado el 16 de octubre de 2014).

-, "Inauguración de la Conferencia Anual 2013, Asia buscando el desarrollo para todos: reestructurando, responsabilidad y cooperación", http://www.presidencia.gob.mx/articulos-prensa/inauguraci on-de-la-conferencia-anual-2013-asia-buscando-el-desarrollo-para-todos-reestructurando-responsabilidad-y-cooperacion/ (consultado el 28 de octubre de 2013).

, "Se reúnen los presidentes de México, Enrique Peña Nieto y de China, Xi Jinping, por tercera ocasión”, http://www.presidencia. gob.mx/articulos-prensa/se-reunen-los-presidentes-de-mexico-enrique-pena-nieto-y-de-china-xi-jinping-por-tercera-ocasion/ (consultado el 19 de febrero de 2014).

, "Firman memorandos de entendimiento para ampliar la cooperación con empresas chinas", http://www.presidencia.gob.mx/ articulos-prensa/firman-memorandos-de-entendimiento-para-ampliar-la-cooperacion-con-empresas-chinas/

, Primer Informe de Gobierno 2012-2013, p. 706-707, http://www. presidencia.gob.mx/descarga-el-resumen-ejecutivo-del-primer-informe/ (consultado el 16 de octubre de 2014).

Putnam, Robert D., "Diplomacy and Domestic Politics: The Logic of Two-Level Games”, International Organization, vol. 42, núm. 3, 1988, pp. $427-460$.

Reporte 98.5, "Vicente Fox Quezada será anfitrión de inversionistas chinos que buscan socios en México" [audio], entrevista a Vicente Fox por Yuridia Sierra, http://www.reporte.com.mx/vicente-fox-quezada-sera-anfitrion-de-inversionistas-chinos-que-buscan-socios-en-mexico (consultado el 13 de abril de 2014).

Rocha Pino, Manuel de Jesús, "La simetría en la Asociación Estratégica República Popular China-Unión Europea”, Estudios de Asia y África, vol. 45, núm.1, enero-abril de 2010.

Sagarpa, "Inicia México exportación de tequila 100\% agave a la República Popular China", http://www.sagarpa.gob.mx/saladeprensa/2012/Pa ginas/2013B508.aspx 
Secretaría de Economía, "Balanza Comercial de México con China", http://200.77.231.38/sic_php/pages/estadisticas/mexicojun2011/ Z3bc_e.html

, "México y China fortalecen diálogo empresarial", http://www. economia.gob.mx/eventos-noticias/informacion-relevante/9994pie291113

_ , "Acuerdan México y China condiciones que regirán las importaciones de calzado proveniente de ese país", Comunicado de prensa núm. 090/12, León, Gto., a 27 de marzo de 2012, http:/ /www.economia.gob.mx/eventos-noticias/sala-de-prensa/comunicados/7655bol-09012 (consultado el 14 de junio de 2014).

, "Establecen México y China Grupo Bilateral de Trabajo de Alto Nivel para Asuntos Económicos", http://www.economia.gob.mx/ eventos-noticias/sala-de-prensa/comunicados/5255-establecenmexico-y-china-grupo-bilateral-de-trabajo-de-alto-nivel-para-asuntoseconomicos (consultado el 16 de octubre de 2014).

Serra Rojas, Andrés, Diccionario de Ciencia Política (M-Z), Facultad de Derecho UNAM-FCE, México, 2001.

SRE, "Nuevos espacios para México en Asia-Pacífico", http://www.sre.gob. $\mathrm{mx} /$ images/stories/doctransparencia/rdc/memodoc/3mddgap. pdf (consultado el 21 de enero de 2014).

_ _ "III Reunión De Diálogo Estratégico y XIII Reunión del Mecanismo de Consultas Políticas México-China”, Comunicado 404 (2013), http://saladeprensa.sre.gob.mx/index.php/comunicados/3316-404 (consultado el 21 de enero de 2014).

, "Ministros de la Alianza del Pacífico y de la Asociación de Naciones del Sudeste Asiático (ANSEA) se reunieron en Nueva York", Comunicado Conjunto SRE-SE, viernes 26 de septiembre de 2014, México, D. F., http://saladeprensa.sre.gob.mx/index.php/es/comunicados/494 $0-429$

Steele, Brent J., "Revisiting Classical Functional Theory: Towards a Twenty-First Century Micro-Politics", Journal of International Political Theory, vol. VII, núm. 1, 2011, pp. 16-39.

Wang, Jianwei, "China's Multilateral Diplomacy in the New Millennium", en Yong Deng y Fei-ling Wang (eds.), China Rising: Power and Motivation in Chinese Foreign Policy, Maryland, Estados Unidos, Rowman \& Littlefield Publishers, Inc., 2005, pp. 159-200. 
Willetts, Peter, "The Cardoso Report on the UN and Civil Society: Functionalism, Global Corporatism, or Global Democracy?”, Global Governance, vol. 12, núm. 3, 2006, pp. 305-324.

Wu, Yongheng, "Apertura del Foro de Diálogo Parlamentario México-China", China Hoy, http:/ / www.chinatoday.com.cn/ctspanish/se/txt/20 10-12/16/content_319457.htm

Xinhua，“背景资料：中国与俄罗斯关系大事记” [Antecedentes: crónica de la relación de China y Rusia], http:/ / news.xinhuanet.com/world/ 2013-03/21/c_115110738.htm

_ , "China, India to Build Strategic Partnership", http://news.xinhuanet.com/english/2005-04/12/content_2819423.htm (consultado el 19 de diciembre de 2013).

Yee, Herbert y Ian Storey, The China Threat: Perceptions, Myths and Reality, Nueva York, RoutledgeCurzon, 2002.

You Ji y Jia Qingguo, “China’s Re-emergence and Its Foreign Policy Strategy”, en Joseph Y.S. Cheng (ed.), China Review 1998, Hong Kong, The Chinese University Press, 1999. 